\title{
Systematic review of dementia prevalence 1994 to 2000
}

\author{
Marcos Antonio Lopes ${ }^{1,2}$, Sérgio Ricardo Hototian ${ }^{2}$, Geraldo C. Reis ${ }^{1}$, \\ Hélio Elkis ${ }^{3}$, Cassio Machado de Campos Bottino ${ }^{2}$
}

\begin{abstract}
Ageing has occurred in all regions of the world, with impact on neuropsychiatric disorders, particularly dementia. However, previous meta-analysis and reviews have shown high variability in world dementia prevalence rates. Objective: The aim of this study was to perform a wide-ranging review of the dementia prevalence studies published in recent years. Methods: The search was made on Medline, Lilacs and Embase databases for research conducted between 1994 and 2000. The main inclusion criteria were: use of standard diagnostic criteria and investigation of community samples. Results: The final selection included 42 papers, from all continents. The mean prevalence rate of dementia in subjects aged 65 years and older, for continents, ranged from $2.2 \%$ in Africa to $8.9 \%$ in Europe, and among countries, from $1.3 \%$ in India to $14.9 \%$ in Spain. However, there was a trend of clustering of the world prevalence rates with the majority of studies reporting rates between $4.2 \%$ and $7.2 \%$ ( $\geq 65$ years). Age directly influenced the rates, with a mean prevalence rate of $1.2 \%$ (95\% CI: $0.8-1.5$ ) for the 65-69 years group and 39.9\% (95\% CI: 34.4-45.3) for the 90-94 year group, but showing less pronounced influence in the very elderly age group. The urban samples had higher rates, where no significant gender difference was evidenced. Conclusion: The age influence over dementia rates apparently leveled off in the very elderly group while a trend toward similar dementia prevalence rates around the world was probably influenced by greater homogeneity in diagnostic criteria.
\end{abstract}

Key words: epidemiology, prevalence, dementia, Alzheimer disease, review.

\section{Revisão sistemática de prevalência de demência - 1994 a 2000}

Resumo - A população idosa vem aumentando em todo o mundo, levando a um impacto nos transtornos psiquiátricos, principalmente os quadros de demência. Contudo, revisões e meta-análises prévias têm mostrado alta variabilidade nas taxas mundiais de prevalência de demência. Objetivo: O objetivo deste estudo foi realizar uma ampla revisão de trabalhos recentes de prevalência de demência. Métodos: O levantamento foi feito em três bases de dados, Medline, Lilacs e EMBASE, no período de 1994 a 2000. Os principais critérios de inclusão foram: uso de critérios diagnósticos padronizados e investigação de amostra comunitária. Resultados: A seleção final incluiu 42 artigos, de todos os continentes. A taxa média de prevalência de demência, na idade maior ou igual a 65 anos, entre continentes, variou de $2.2 \%$ na África, até $8.9 \%$ na Europa, e entre países, de 1.3\% na Índia, até $14.9 \%$ na Espanha. Contudo, a maioria dos estudos reportou taxas entre $4.2 \%$ e $7.2 \%$ ( $\geq 65$ anos). A idade exerceu influência direta sobre as taxas de prevalência, com taxas médias de 1.2\% na faixa etária 65-69 anos, e $39.9 \%$ na faixa etária 90-94 anos, mostrando, no entanto, um efeito menos pronunciado nos idosos muito idosos. A população de procedência urbana teve taxas significativamente maiores, e não houve diferença significativa entre os sexos. Conclusão: A influência da idade sobre as taxas de prevalência de demência diminuiu entre os idosos mais "idosos", e a tendência de resultados similares em todo o mundo provavelmente foi influenciada pela homogeneidade nos critérios diagnósticos.

Palavras-chave: epidemiologia, prevalência, demência, doença de Alzheimer, revisão.

The world ageing process impacts certain diseases, and in recent years researchers from many countries have studied the prevalence and risk factors associated with dementia, especially Alzheimer disease (AD).
A significant number of dementia prevalence studies have been carried out in recent decades and published data have been analyzed by reviews and meta-analyses. Since the influential review published by Jorm et al. (1987), ${ }^{1}$

${ }^{1}$ Clinics Hospital, Department of Neurology, Psychiatry and Medical Psychology of Faculty of Medicine of Ribeirão Preto, University of São Paulo, Brazil. ${ }^{2}$ Old Age Research Group (PROTER), Institute of Psychiatry, Faculty of Medicine, University of São Paulo, Brazil. ${ }^{3}$ Department of Psychiatry, Faculty of Medicine, University of São Paulo, Brazil.

Marcos Antonio Lopes - Clinics Hospital, Department of Neurology, Psychiatry and Medical Psychology - Bandeirantes Avenue, 3900 / Campus of USP 14049-900 Ribeirão Preto SP - Brazil. E-mail: lopes@netsite.com.br 
which showed the strong effect of age on dementia prevalence, the descriptive review of Fratiglioni et al. (1999), ${ }^{2}$ reporting that Vascular Dementia (VD) is more prevalent than Alzheimer disease in Asian countries and the European review by Lobo et al. (2000), ${ }^{3}$ observing Alzheimer disease as the major cause for the fast increase of dementia in the elderly, a high variability of dementia prevalence rates has been observed around the world. However previous reviews have either shown studies with broad diagnoses or specific characteristics (such as same region) or have evaluated a single variable. A wide-ranging review which evaluates recent studies and has high homogeneity in research methods, including diagnostic criteria, can help researchers to understand the factors influencing the distribution of dementia rates throughout different regions of the world.

The purposes of this study were: 1) to review worldwide dementia prevalence studies from 1994 to $2000 ; 2$ ) to assess and to integrate dementia prevalence rates, evaluating its distribution related to demographic factors; 3 ) to assess prevalence rates of both main etiological subtypes of Dementia, namely: Alzheimer disease and Vascular Dementia; 4) to assess the influence of methodological variables on dementia prevalence rates; 5) to analyse the relationship between dementia prevalence and the variables studied, in order to detect possible associations which could be addressed in future researches.

A preliminary analysis of the data presented in this article, without statistical analysis, was published previously. ${ }^{4}$

\section{Methods}

\section{Survey of studies}

Studies published between 1994 and 2000 were obtained from 3 data bases: Medline, Lilacs and EMBASE. In step one all languages were considered. The terms "epidemiology", "prevalence" and "dementia" were used in "all fields". All articles were sent for selection, according to specific criteria. Two examiners working independently performed the selection on the Medline database (M.A.L. and S.R.H).

\section{Selection of studies}

Studies were selected in 3 phases, with the following inclusion criteria:

- $1^{\text {st }}$ phase: Original articles that have estimated dementia prevalence in community samples using internationally accepted diagnostic criteria for "Dementia Syndrome", according to most recent diagnostic manuals, chiefly the DSM-III-R, DSM-IV, ICD-10 or similar (very broad diagnoses were excluded, such as "organic cerebral syndrome" or "organic mental disorder").
- $2^{\text {nd }}$ Phase: Articles written in English, Portuguese, and Spanish; accessibility.

- $3^{\text {rd }}$ Phase: Data presented in a way that permitted comparison between studies.

\section{Characterization of the studies evaluated}

The following variables were recorded for each study: authors, country of origin, publication year, age range studied, sample composition (inclusion of institutionalized subjects, urban or rural provenance), total sample size, loss of subjects, sub-sample size by age group and gender, dementia prevalence in elderly aged 65 years and older and at 5-year intervals, prevalence in each gender and age interval, prevalence of Alzheimer disease and Vascular Dementia etiological diagnoses, diagnostic criteria, use of computerized tomography and laboratorial exams.

\section{Data investigation}

Descriptive analysis

The studies were initially gathered on six geographic areas. Crude mean prevalence and distribution with regard to age group, gender and etiology were evaluated for each geographic area, within each country and among the countries. Although the means were not adjusted, only studies with prevalence rates in elderly aged 65 years and older were taken into account. Exception was made when analysing the age variable, whereby only those studies with specific age ranges (65-69, 70-74 and so on) were investigated, and for the etiology variable for which 3 studies with age range of 100 years and older were separately analysed.

\section{Statistical analysis}

Univariate analysis: initially, the age effect over prevalence rates was examined, and three statistics models that could best represent the data were tested, following the methodology used by Ritchie and Kildea (1995). ${ }^{5}$ Three functions were applied - exponential, logistic and modified logistic - to obtain a general model that would be able to estimate the relationship between the variables "dementia prevalence" and "age". The mean prevalence for each age group was calculated for this procedure and adjustments were made for the size of each age range (number of subjects). Age information was based on age group intervals defined in the studies $(65-69,70-74,75-79 . .$.$) , and$ were codified in the present analysis from the approximate midpoint $(67.5,72.5,77.5 \ldots)$. $\mathrm{R}^{2}$ was calculated for each function (this statistics gives a percent variation of the prevalence "explained" by age, and can be used both for verifying if the adjustment is adequate or not, and for comparison between different adjustments). Following the univariable analysis, the mean of each category of a vari- 
able was calculated and compared with the mean of other categories of the same variable. According to this strategy, the analysis of the variables "sample type" (community or institution+community), "provenance" (urban or rural), and "gender" was performed. Additionally, an adjustment to the variable "age" was made, where each variable cited above was investigated for each age group intervals. The Bonferroni method was then applied, in which the $0.05 \mathrm{p}$ value was divided by 21 ( 3 variables and 7 age ranges) in order to obtain a new $\mathrm{p}$ value corresponding to the statistical significance. Without the adjustment for the "age" variable, the variables "sample size", "percentage of participation" and "percentage of loss" were also examined. Non-parametric tests were used, considering that the data did not show a normal distribution. The Mann-Whitney test was used for the variables with two categories such as "sample type" (community, community+institution), and "gender". The Kruskal-Wallis test was used for the variable with three categories namely, "provenance" (urban, urban+rural, rural) while the Spearman non-parametric correlation coefficient was applied for continuous variables such as "sample size", "percentage of participation" and "percentage of loss". The same tests outlined above were used in the analysis of the variables "sample type, "gender" and "provenance', for all age group intervals.

\section{Multivariate analysis}

Finally, multivariable analysis was performed using the variables "age, "gender", "sample type", "provenance", "use of computerized tomography", "use of laboratorial exams", "use of total population", "use of DSM", --8 "use of Hachinski Ischemic Scale" and "use of NINCDS-ADRDA diagnostics criteria". ${ }^{10}$ The variable "use of NINCDS-ADRDA criteria" was chosen according to the methodology described in the reviews, as the possible interference of diagnostic criteria in dementia prevalence rates was considered. Logistic regression was performed with the Proc Logistic section of the SAS program. This choice of mathematical model took into consideration that the dependent variable was dichotomic - "with dementia" or "without dementia" - and that many independent variables could have potential influence on dementia prevalence rate, as described above. The data were considered for Logistic Regression following this strategy: lines for all age ranges of all studies; each two lines referred to the same age range and the same study, one line for male and another line for female; the first column for the "age" variable (age range); second column for number of cases of dementia; third column for total number of people; the next columns for the other variables. Adjusted "odds ratios" were estimated, with the respective confidence intervals and ' $\mathrm{p}$ ' values.

\section{Results \\ Selection and utilization of studies}

1750 articles were found, from which 73 were initially selected, according to the criteria established in the first phase of the selection. Eight articles in other languages were excluded (Dutch: four; Japanese: two; German: one; and Polish: one), and two articles could not be accessed ( $2^{\text {nd }}$ Phase). In the third phase of the selection, 15 articles were excluded: 12 , for using age group different from " 65 years and older", or age intervals different from the majority of other studies; two, for examining specific samples (male gender, retired); and one, for estimating prevalence of moderate and severe degrees of dementia only. In total, 42 articles were finally studied, as shown in Table 1.

The studies were partly used in that, for each evaluation, only one set of articles was used since not all the data studied in these articles were available. In the descriptive analysis for variables "prevalence of dementia", "age", "gender" and "Alzheimer disease / Vascular Dementia Ratio", 26 212-19,29-38,41-46,50,51, $26^{11-18,20-24,25,27,29,31,32,3,34,37,39,43,45,47,51,52}, 19^{13-15,17-19,29-32,34-38,43,45,46,51}$ and $21^{15-18,26,29-32,34-38,40,41,43,46,48,50,51}$ articles out of the total number of articles selected were used, respectively.

\section{Descriptive analysis}

The distribution by geographic area was defined as follows:

- Europe: 16 studies (Spain: four, Italy: four, Holland: two, Germany: two, England: one, Sweden: one, Denmark: one, Belgium: one).

- Asia: 14 studies (Japan: six, Taiwan: three, Korea: two, India: two, Hong-Kong: one).

- North America: 8 studies (United States: six, Canada: two).

- Africa: 2 studies (Nigeria: one, Egypt: one).

- South America: 1 study (Brazil: one).

- Oceania: 1 study (Australia: one).

\section{Social-demographic distribution}

The mean dementia prevalence rates, in elderly aged 65 years and older, were 2.2\% in Africa, 5.8\% in Asia, 6.2\% in North America, $7.1 \%$ in South America, up to $8.9 \%$ in Europe. In Nigeria, one of the lowest results was described, $2.2 \%{ }^{50}$, below rates in the American study ${ }^{41}$ that included subjects classified as "African-American".

Studies performed in Asian countries presented great variability in their results, in the same country and among different countries. For example, in Taiwan the mean prevalence was $3.3 \%$, with results varying between $2.0 \%^{38}$ and $4.4 \%{ }^{36}$ In Japan, the mean prevalence was $6.7 \%$, with results ranging from $5.5 \%{ }^{30}$ to $8.5 \%,{ }^{32}$ and in Korea the mean prevalence was $10.1 \%$, with the lowest variation among the studies reviewed. The highest result among Japanese stud- 
Table 1. Worldwide dementia prevalence studies, from 1994 to 2000.

\begin{tabular}{|c|c|c|c|c|c|c|c|c|c|}
\hline Author & Year & Country & Sample & Age & Prevalence (\%) & Diagn & ostic & & \\
\hline Ott et al. ${ }^{11}$ & 1995 & Holland & 7528 & $\geq 55$ & 6.3 & a c & & & \\
\hline Prencipe et al. ${ }^{12}$ & 1996 & Italy & 1022 & $\geq 65$ & 8.0 & a c & $\mathrm{f}$ & & \\
\hline Boersma et al. ${ }^{13}$ & 1998 & Holland & 2191 & $\geq 65$ & 6.5 & $\mathrm{a}$ & $d$ & & \\
\hline Brayne et al. ${ }^{14}$ & 1998 & England & 2622 & $\geq 65$ & 6.6 & & $\mathrm{e}$ & & $\mathrm{k}$ \\
\hline Andersen et al. ${ }^{15}$ & 1997 & Denmark & 3346 & $\geq 65$ & 7.1 & a c & $\mathrm{f}$ & & \\
\hline Roelands et al. ${ }^{16}$ & 1994 & Belgium & 1736 & $\geq 65$ & 9.0 & a $\quad d$ & & & \\
\hline Lobo et al. ${ }^{17}$ & 1995 & Spain & 1134 & $\geq 65$ & 5.5 & $\mathrm{a}$ & $\mathrm{e}$ & & \\
\hline Pousa et al. ${ }^{18}$ & 1995 & Spain & 273 & $\geq 65$ & 13.9 & $\mathrm{~d}$ & $d$ & & \\
\hline Pi et al. ${ }^{19}$ & 1996 & Spain & 516 & $\geq 65$ & 14.9 & a & & g & \\
\hline Manubens et al. ${ }^{20}$ & 1995 & Spain & 1127 & $\geq 70$ & 17.7 & a cd & & & \\
\hline Wernicke and Reischies ${ }^{21}$ & 1994 & Germany & 156 & $\geq 70$ & 11.7 & $\mathrm{a}$ & & & \\
\hline DAlessandro et al. ${ }^{22}$ & 1996 & Italy & 365 & $\geq 75$ & 21.9 & a & ef & & \\
\hline Azzimondi et al..$^{23}$ & 1998 & Italy & 773 & $\geq 75$ & 28.4 & a & ef & & \\
\hline Strauss et al. ${ }^{24}$ & 1999 & Sweden & 1848 & $\geq 77$ & $19.3^{\ddagger}$ & $\mathrm{a}$ & & & \\
\hline Fichter et al. ${ }^{25}$ & 1995 & Germany & 402 & $\geq 85$ & 27.8 & $\mathrm{ab}$ & & & \\
\hline Ravaglia et al. ${ }^{26}$ & 1999 & Italy & 154 & $\geq 100$ & 61.9 & $\mathrm{abc}$ & $\mathrm{f}$ & & \\
\hline Shaji et al. ${ }^{27}$ & 1996 & India & 2067 & $\geq 60$ & 3.1 & $\mathrm{ab}$ & & & \\
\hline Yamada et al. ${ }^{28}$ & 1999 & Japan & 2934 & $\geq 60$ & 7.2 & $\mathrm{a} \quad \mathrm{c}$ & & & \\
\hline Komahashi et al. ${ }^{29}$ & 1994 & Japan & 2778 & $\geq 65$ & 6.1 & a & $\mathrm{e}$ & & \\
\hline Kiyohara et al. ${ }^{30}$ & 1994 & Japan & 1189 & $\geq 65$ & $5.5^{\ddagger}$ & a & & & \\
\hline Ogura et al. ${ }^{31}$ & 1995 & Japan & 3524 & $\geq 65$ & 6.7 & a c & e & & \\
\hline Shiba et al. ${ }^{32}$ & 1999 & Japan & 201 & $\geq 65$ & 8.5 & a c & e & & \\
\hline Chandra et al. ${ }^{33}$ & 1998 & India & 536 & $\geq 65$ & 1.3 & & $\mathrm{f}$ & $\mathrm{i}$ & \\
\hline Park et al. ${ }^{34}$ & 1994 & Korea & 766 & $\geq 65$ & 10.8 & a & $\mathrm{e}$ & & \\
\hline Woo et al. ${ }^{35}$ & 1998 & Korea & 2171 & $\geq 65$ & 9.5 & $\mathrm{a} \quad \mathrm{c}$ & e & & \\
\hline Liu et al. ${ }^{36}$ & 1996 & Taiwan & 1200 & $\geq 65$ & 4.4 & a c & & $\mathrm{h}$ & \\
\hline Lin et al. ${ }^{37}$ & 1998 & Taiwan & 4015 & $\geq 65$ & 3.7 & b c & $\mathrm{e}$ & h i & \\
\hline Liu et al. $^{38}$ & 1995 & Taiwan & 5297 & $\geq 65$ & 2.0 & a & & & \\
\hline Chiu et al. ${ }^{39}$ & 1998 & Hong Kong & 1034 & $\geq 70$ & 6.1 & a d & & & \\
\hline Asada et al. ${ }^{40}$ & 1996 & Japan & 47 & $\geq 100$ & 70.2 & $\mathrm{abc}$ & & & \\
\hline Hendrie et al. ${ }^{41}$ & 1995 & USA & 4812 & $\geq 65$ & 4.8 & $\mathrm{abc}$ & & & \\
\hline Beard et al. ${ }^{42}$ & 1995 & USA & ${ }^{\S} \mathrm{REP}$ & $\geq 65$ & 5.7 & & & & \\
\hline Graves et al. ${ }^{43}$ & 1996 & USA & 1985 & $\geq 65$ & 6.3 & a c & $\mathrm{f}$ & & \\
\hline Fillenbaum et al. ${ }^{44}$ & 1998 & USA & 4236 & $\geq 65$ & $7.0-7.2$ & $\mathrm{a} \quad \mathrm{c}$ & & & \\
\hline Breitner et al. ${ }^{45}$ & 1999 & USA & 5677 & $\geq 65$ & 9.6 & $\mathrm{a} \quad \mathrm{c}$ & & hi & \\
\hline McDowell et al. ${ }^{46}$ & 1994 & Canadá & 10263 & $\geq 65$ & 4.2 & $\mathrm{abc}$ & & & \\
\hline Ebly et al. ${ }^{47}$ & 1994 & Canadá & 4510 & $\geq 85$ & 28.5 & $\mathrm{abc}$ & e & & \\
\hline Powell $^{48}$ & 1994 & USA & 40 & $\geq 100$ & 57.5 & & $\mathrm{f}$ & & \\
\hline Farrag et al. ${ }^{49}$ & 1998 & Egypt & 2000 & $\geq 60$ & 4.5 & a c & e & & \\
\hline Ogunniyi et al..$^{50}$ & 1997 & Nigeria & 2494 & $\geq 65$ & 2.2 & $a b c$ & & & \\
\hline Herrera Jr. et al. ${ }^{51}$ & 1998 & Brazil & 1660 & $\geq 65$ & 7.1 & $\mathrm{a} \quad \mathrm{c}$ & ef & $\mathrm{h}$ & \\
\hline Henderson et al. ${ }^{52}$ & 1994 & Australia & 1377 & $\geq 70$ & $7.3^{\ddagger}$ & $a b$ & & & \\
\hline
\end{tabular}

${ }^{\dagger}$ Diagnostic Criteria and Instruments: (a) "Diagnostic and statistical manual of mental disorders, $3^{\text {rd }}$ ed. rev" (DSM-III-R) ${ }^{7}$ ou "Diagnostic and statistical manual of mental disorders, $4^{\text {th }}$ ed." (DSM-IV); $;^{8}$ (b) International of Classification of Diseases ICD-1053; (c) "National Institute of Neurological and Communicative Disorders and Stroke and the Alzheimer's Disease and Related Disorders Association (NINCDS-ADRDA)"; ${ }^{10}(\mathrm{~d})$ "Cambridge Mental Disorders of the Elderly Examination" (CAMDEX); ${ }^{54}$ (e) Hachinski Ischemic Scale (HIS); ; (f) "Clinical Dementia Rating" (CDR); ${ }^{55}$ (g) "Blessed Dementia Scale" (BDS) ${ }^{56}(\mathrm{~h})$ "National Institute of Neurological Disorders and Stroke and Association Internationale pour la Recherche et l'Enseignement en Neurosciences (NINDS-AIREN); ${ }^{57}$ (i) “The Consortium to Establish a Registry for Alzheimer's Disease" (CERAD); ${ }^{58}$ (j) "Rochester Epidemiologic Project" (REP); (k) AGECAT (Automated Geriatric Examination for Computer Assisted Taxonomy). ${ }^{59}{ }^{\ddagger}$ Crude rate. ${ }^{5}$ Linear interpolation from decennial census data (1970 to 1990 ). 
ies $(8.5 \%)^{32}$ occurred in a rural region. The highest prevalence in Asian countries was $10.8 \%,{ }^{34}$ also in a rural zone, in a very economically limited Korean community.

Great variability was found in the North American results. The prevalence varied between $4.8 \%{ }^{41}$ and $9.6 \%,{ }^{45}$ with a mean of $6.7 \%$. Among investigations, Fillenbaum et al. $(1998)^{44}$ and Hendrie et al. $(1995)^{41}$ studies are noteworthy. In the first study, almost no differences were observed between African and White Americans (7.0 and 7.2\% respectively), while in the second study, a high prevalence in African-American subjects was described (4.8\%) compared with rates for Africans living in Africa (2.2\%). ${ }^{41,50}$ The Canadian study described a prevalence of $4.2 \%{ }^{46}$

The results of European studies, estimating prevalence in 65 years and older, were as follows: Holland: $6.5 \% ;^{13}$ England: $6.6 \%{ }^{14}$ Denmark: $7.1 \% ;{ }^{15}$ Italy: $8.0 \%{ }^{12}$ Belgium: 9.0\% ${ }^{16}$ and Spain: $5.5 \%,{ }^{17} 13.9 \%{ }^{18}$ and $14.9 \% .{ }^{19}$ The mean in Europe was very high at $8.9 \%$, strongly influenced by two Spanish studies, ${ }^{18,19}$ that investigated rural and rural/ urban population, and found the highest rates of all the European studies.

In the Brazilian study, the only study selected in South America, the authors described a rate of dementia prevalence of $7.1 \% .^{51}$

Dementia prevalence increased with age in all regions, except North America (a study conducted in the USA) ${ }^{48}$, for the group aged 100 years and older, where a lower rate was noted compared to the preceding age group (Figure 1). Mean rates of dementia prevalence, worldwide and by region, did not increase at such a high rate in the oldest age groups compared to other age groups (Table 2).

Higher dementia prevalence was observed in the female gender, across all regions studied. In some studies the ratio was two women to every one man. However, approximately $25 \%$ of the studies described higher prevalence in male gender with these differences not reaching statistical significance. Fillenbaum et al. (1998) ${ }^{44}$ observed a slight predominance of the male gender, which was not statistically significant, in dementia cases for African-Americans, in contrast to the result observed for White Americans. Ogunniyi et al. (1997), ${ }^{50}$ in Nigeria, found an overwhelming prevalence of male gender (6:2 ratio) in Vascular Dementia cases.

Prevalence of Alzheimer disease was higher than Vascular Dementia in all researched regions, particularly in the South-American study ${ }^{51}$ which presented results two to three times higher than in other regions. An important inversion of this relationship occurred in $25 \%$ of the Asian studies, with VD prevalence described in two studies as two times greater than AD. The age effect over these two etiologic diagnoses was also evident, verifying that the $\mathrm{AD} /$

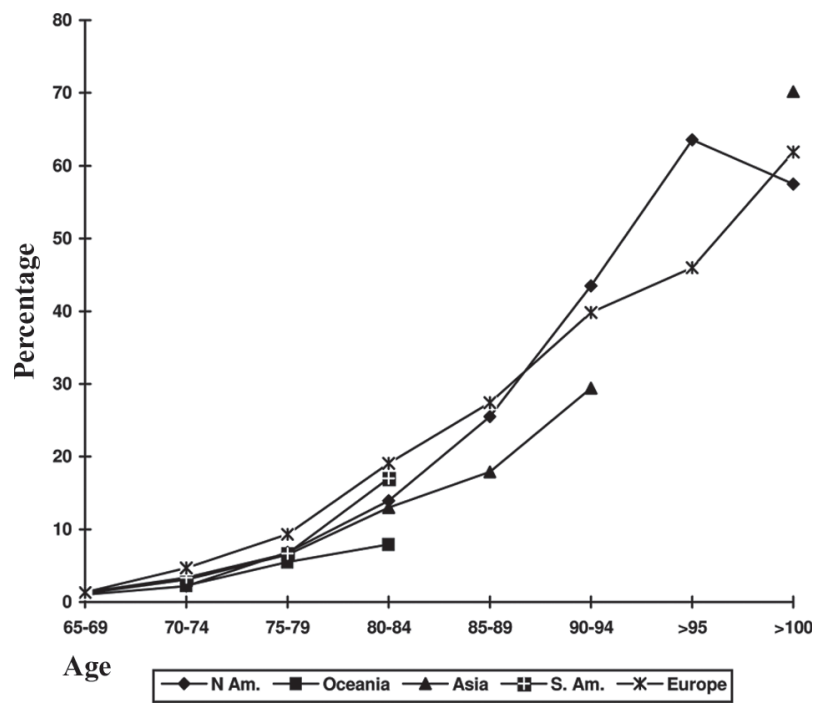

Figure 1. Dementia prevalence rate (mean), in each region.

Table 2. Effect of age over dementia prevalence rates. Crude mean rate in each age group (\%) and amount of the increase of rates, as age increases (times).

\begin{tabular}{ccccc}
\hline Age & $\begin{array}{c}\mathbf{N} \\
(\text { studies })\end{array}$ & $\begin{array}{c}\text { Mean } \\
\text { rate }(\%)^{\dagger}\end{array}$ & $(\mathbf{9 5} \% \mathbf{C I})$ & $\begin{array}{c}\text { Increase } \\
\text { of rates }^{\ddagger}\end{array}$ \\
\hline $65-69$ & 17 & 1.2 & $(0.8-1.5)$ & \\
$70-74$ & 19 & 3.7 & $(2.6-4.7)$ & 3.0 \\
$75-79$ & 21 & 7.9 & $(6.2-9.5)$ & 2.1 \\
$80-84$ & 20 & 16.4 & $(13.8-18.9)$ & 2.0 \\
$85-89$ & 16 & 24.6 & $(20.5-28.6)$ & 1.5 \\
$90-94$ & 6 & 39.9 & $(34.4-45.3)$ & 1.6 \\
$>95$ & 6 & 54.8 & $(45.6-63.9)$ & 1.3 \\
\hline
\end{tabular}

${ }^{\dagger}$ Mean dementia prevalence rate; ${ }^{\ddagger}$ Amount of increase of rates, in comparison with rate before.

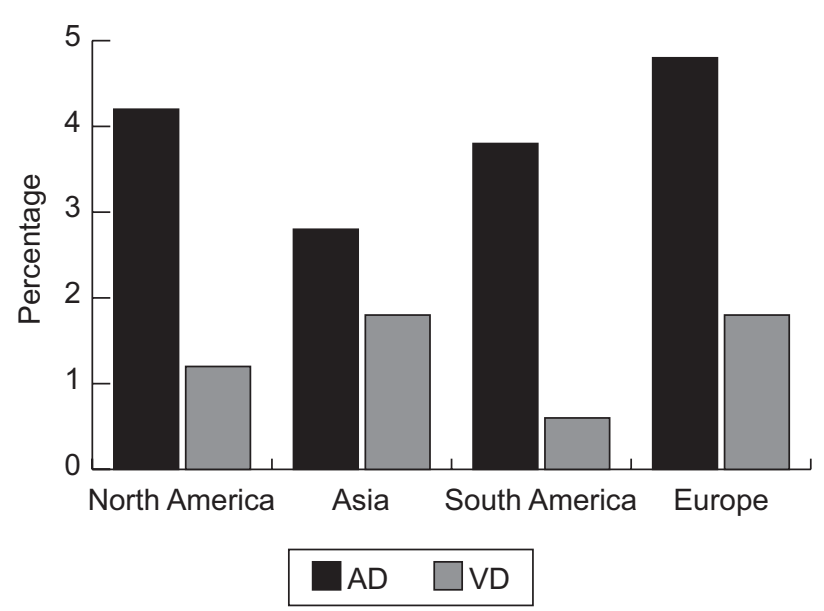

Figure 2. Crude mean rate of Alzheimer's disease $(A D)$ and vascular dementia (VD) in each region, in elderly aged 65 years and older. 


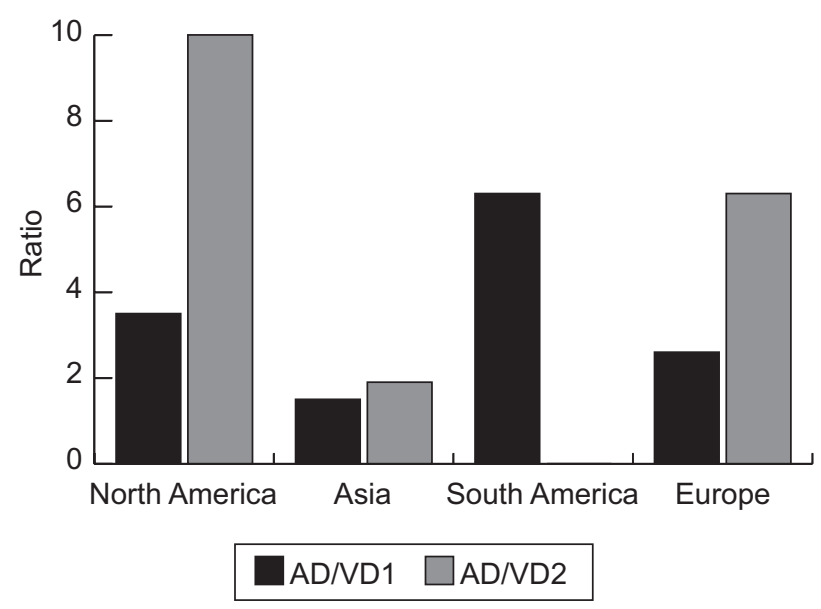

Figure 3. Ratio Alzheimer's disease $(A D)$ and vascular dementia $(V D)$ in each region, in elderly aged 65 years and older (AD/VD 1) and in 100 years and older (AD/VD 2).

VD ratio showed an important increase in centenarians (Figures 2 and 3).

Predominance of Vascular Dementia over Alzheimer disease, identified as a tendency in Japan by Komahashi et al. (1994), ${ }^{29}$ was not observed in the Ogura et al. (1995) study, ${ }^{31}$ where an Alzheimer disease/Vascular Dementia ratio of 1.5:1 was found. Kiyohara et al. (1994), ${ }^{30}$ despite reporting a higher prevalence of $\mathrm{VD}$ over $\mathrm{AD}$, verified a significant increase in $\mathrm{AD} / \mathrm{VD}$ rate over a 7-year-period.

The AD/VD ratio among African-Americans was similar to those in most of the Western world studies, standing at around 1.5:1. When African-Americans were compared to White Americans, the results were also equivalent.

Approximately $30 \%$ of the studies used solely the MiniMental State Examination" (MMSE) (Folstein et al., 1975), ${ }^{60}$ for detection of probable dementia cases. Eighty-four percent of the studies utilized criteria from the "Diagnostic and Statistical Manual of Mental Disorders", from the American Psychiatry Association (versions III-R or IV), ${ }^{7,8}$ and $50 \%$ of

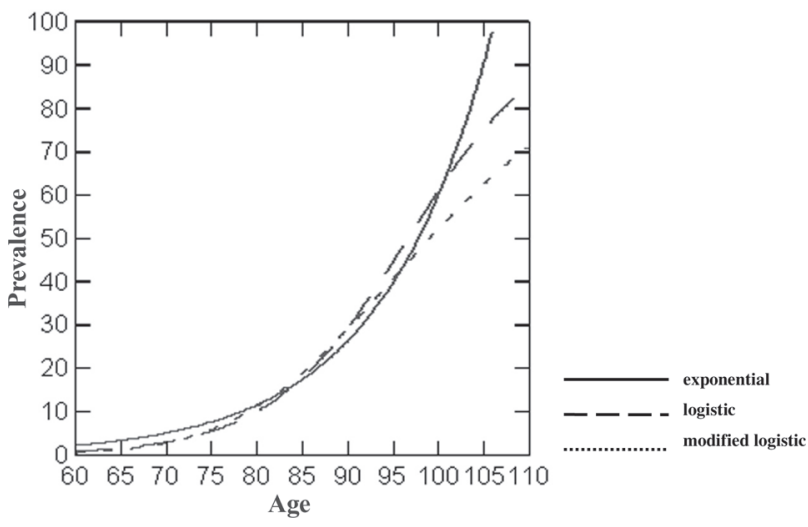

Figure 4. Age influence over dementia prevalence exponential, logistig and modified logistic models.

these studies also used the NINCDS-ADRDA criteria. ${ }^{10}$ Fifty-four percent of the studies used at least one scale or additional criteria for Vascular Dementia (Hachinski Ischemic Scale, ${ }^{9}$ in the majority of the studies, or NINDS-AIREN ${ }^{57}$ ).

\section{Statistical analysis}

Univariate analysis

Age - The estimated average prevalence rate and the examined functions, for each age group interval, can be seen in Table 3. All three models permitted excellent adjustments, both by $\mathrm{R}^{2}$ values and by estimated values, but the modified logistic was the most efficient, especially when estimated values for each model were compared. It was also noted that the modified logistic model yielded prevalence estimates closer to observed rates. In contrast to the exponential model, both logistic and the modified logistic models presented an inflection point on the resulting graphic (Figure 4), the inflection point in the modified logistic model being prior to the one in the logistic model. In the modified logistic model the highest prevalence rates were reached for higher ages than in the logistic model.

Table 3. Effect of age over dementia prevalence rates, according to three statistical models. Rates in observed prevalence and in three models are expressed in percentage (\%).

\begin{tabular}{ccccc}
\hline Age $^{\dagger}$ (years) & Prevalence (\%) & Exponential & Logistic & Modified logistic \\
\hline 67.5 & 1.75 & 4.01 & 2.04 & 2.01 \\
72.5 & 3.84 & 6.10 & 3.81 & 4.42 \\
77.5 & 7.55 & 9.18 & 6.98 & 8.79 \\
82.5 & 14.74 & 13.81 & 12.46 & 15.36 \\
87.5 & 24.08 & 20.78 & 21.25 & 26.43 \\
95.5 & 37.98 & 39.95 & 42.90 & 41.01 \\
$\mathrm{R}^{2 \ddagger}(\%)$ & & 96.7 & 98.2 & 99.2 \\
\hline
\end{tabular}

${ }^{\dagger}$ Midpoint between 65-69, 70-74, 75-79, 80-84, 85-89, 90-100; ${ }^{*}$ Refers to amount changes as function of age. 
Table 4. Effect of 'sample' (community or community + institution), 'provenace' (urban or urban+rural or rural) and 'gender' over rates.

\begin{tabular}{lcccc}
\hline Variable & $\begin{array}{c}\text { Mean } \\
(\%)\end{array}$ & $\begin{array}{c}\text { Median } \\
(\%)\end{array}$ & SD & $\begin{array}{c}\text { Statistic } \\
\mathbf{p}\end{array}$ \\
\hline Community & 10.8 & 8.0 & 10.5 & Mann-Whitney \\
Com.+Instit. & 17.3 & 12.2 & 16.6 & $0.03^{\dagger}$ \\
Urban & 18.1 & 11.3 & 17.3 & Kruskal-Wallis $^{+}$ \\
Urban+rural & 8.5 & 5.4 & 8.7 & $0.02^{\dagger}$ \\
Rural & 12.8 & 10.0 & 11.9 & \\
Female & 15.8 & 10.7 & 16.3 & Mann-Whitney \\
Male & 12.4 & 9.1 & 11.9 & 0.48 \\
\hline
\end{tabular}

${ }^{\dagger}$ Significant statistically.

Table 5. Effect of demographic and clinical variables over rates, after multivariate analysis.

\begin{tabular}{lccc}
\hline Variable & Odds ratio adjusted & C.L.95\% & p \\
\hline Age & 1.15 & $1.14-1.16$ & $<0.0001^{\dagger}$ \\
Female & 1.10 & $0.99-1.22$ & 0.0557 \\
Community + institution & 1.31 & $1.00-1.69$ & $0.0426^{\dagger}$ \\
Urban & 1.76 & $1.39-2.22$ & $<0.0001^{\dagger}$ \\
Rural & 1.38 & $1.14-1.68$ & $<0.0001^{\dagger}$ \\
Computerized tomography & 0.50 & $0.39-0.65$ & $<0.0001^{\dagger}$ \\
Laboratory & 1.51 & $1.13-2.02$ & $0.0053^{\dagger}$ \\
All population & 1.28 & $1.07-1.53$ & $0.0071^{\dagger}$ \\
DSM & 0.99 & $0.75-1.30$ & 0.9494 \\
Hachinski ischemic scale & 0.71 & $0.59-0.87$ & $0.0009^{\dagger}$ \\
NINCDS-ADRDA & 1.08 & $0.92-1.28$ & 0.3143 \\
\hline
\end{tabular}

${ }^{\dagger}$ Significant statistically.

Sample type (community or institution), provenance (urban or rural), gender - Studies investigating community+ institution samples and samples from urban provenance, presented significantly higher prevalence rates compared to community alone and samples from urban-rural provenance, respectively. The female gender presented higher rates than male, but this was not statistically significant (Table 4). There was one negative correlation between prevalence rates and the variables "sample size". (r: -0.62 ; $\mathrm{p}<0.01$; statistically significant) and "participation rate" ( $\mathrm{r}$ : -0.41 ; p:0.06; tendency of association).

When the variables "sample type", "provenance" and "gender" were analysed in each age group, no statistically significant association was found.

\section{Multivariate analysis}

The logistic regression method allowed analysis of how "age,, "gender", "sample type", "provenance", "use of computerized tomography", "use of laboratorial exams", "use of total population", "use of DSM", 6-8 "use of Hachinski Ischemic Scale" and "use of NINCDS-ADRDA diagnostic criteria"10 influenced prevalence rates, and adjusted for each other. Age influenced prevalence rates significantly where age and prevalence rates increased hand-in-hand. Studies with community+institution sample type, rural provenance, "use of total population" and "use of laboratorial exams" presented significantly higher prevalence rates. Studies that used computerized tomography and Hachinski Ischemic Scale presented significantly lower prevalence rates. Variables such as "gender", "use of DSM" and "use of NINCDS-ADRDA", did not present statistically significant differences (Table 5).

\section{Discussion}

Methodological advances were evident from the great number of studies that used standardized diagnostic criteria for diagnoses of dementia and its main causes: Alzheimer disease and Vascular Dementia. On the other 
hand, with relation to the method for detection of probable cases of dementia, the "Mini-Mental of State Examination" $(\mathrm{MMSE})^{60}$ was applied alone in a considerable number of studies. Such strategy is questionable, in view of the effects of age and schooling on the performance of the MMSE.

Results differed significantly both within the same region, and within the same country. Greatest differences within the same region appeared in Asia, where Chandra et al. $(1998)^{33}$ described a prevalence rate of $1.3 \%$ in India, while Park et al. $(1994)^{34}$ reported a rate of $10.8 \%$ in Korea. However, 14 of the 26 studies reporting dementia prevalence in subjects aged 65 years and older, investigating a total of 40.940 elderly in the community, reported rates ranging from $4.2 \%$ to $7.2 \%$. Similarly, there seemed to be a worldwide tendency to report similar rates of dementia prevalence in elderly aged 65 and older (the 14 above-mentioned studies were performed in all researched regions, except Africa). Another illustration of worldwide similarity was the increased rates of prevalence of dementia correlated with increased age in all researched regions (except Africa, due to insufficient data for comparison). There was insufficient evidence to elucidate the causes underlying the extreme dementia rates mentioned, or to assure the available data indicated "true" regional differences, or differences caused by methodological bias.

The results on the variable provenance were controversial. While in the descriptive analysis higher prevalence rates among Japanese, ${ }^{32}$ Asian ${ }^{34}$ and European ${ }^{19}$ subjects were found in rural samples, on the univariable and multivariable analyses, higher prevalence rates were associated to urban provenance as was stated by Jorm et al. (1987). ${ }^{1}$ Regarding the descriptive analysis, it is important to point out the small sample size in the two Spanish studies ${ }^{18,19}$ (with the highest rates found in Europe), which increased the risk of inaccuracy of the results obtained. Controlling the interference of the variables reported in the present review, other factors could possibly explain the association between urban population and higher dementia rates such as lower mortality and other conditions that might be typical of rural populations, but which can also be present in elderly samples living in urban areas, such as poor education $^{12,22,23,34,35}$ (intrinsic factor and not a methodological bias), inadequate mental stimulation, ${ }^{34}$ manual occupation in the past ${ }^{23}$ (closely related to the previous factor), poor diet, ${ }^{34}$ limited access to medical care. ${ }^{32}$

In the present study, the descriptive analysis of the gender variable confirmed a tendency described earlier by Jorm et al. (1987) ${ }^{1}$ and recently by Lobo et al. (2000). ${ }^{3}$ The higher prevalence of dementia in the female gender resulted mainly from the distribution of Alzheimer disease in $75 \%$ of the studies reviewed. However, the multivariable analy- sis did not demonstrate a significant difference between the variable "gender" and prevalence rates, although the "p" value was close to 0.05 , indicating a tendency of higher prevalence rates for the female gender. It is not possible to explain whether there is a higher risk for women of developing Alzheimer disease by exclusively examining prevalence studies. Hebert et al. (2001), ${ }^{61}$ in an interesting study compared prevalence and incidence of Alzheimer disease between two populations resident in Boston, USA. The results demonstrated that incidence and prevalence of Alzheimer disease, controlling for age, were not significantly different between men and women. In conclusion, the authors declared that higher prevalence rates of women with Alzheimer disease could be due to women's higher life span, and not related to any specific risk factor associated to gender.

The use of diagnostic instruments did not influence uniformly the rates of prevalence of dementia, similar to the findings reported by Corrada et al. (1995), ${ }^{62}$ in the study of sources of variability on rates of prevalence of Alzheimer disease. However, the argument that Corrada et al. $(1995)^{62}$ presented, that computerized tomography and the Hachinski Ischemic Scale ${ }^{9}$ contributed to diagnosing cases of Vascular Dementia in subjects with Alzheimer disease, lowering their prevalence rates, could not be applied to the results of the present study, which investigated the influence on prevalence rates of dementia, and not Alzheimer disease. Thus, it raised the hypothesis that factors other than the relationship between Vascular Dementia and Alzheimer disease could explain that association.

The relationship Alzheimer disease/Vascular Dementia appeared considerably higher in South America. ${ }^{51}$ This finding may have been influenced by two main aspects: a "true" low prevalence of Vascular Dementia in this sample, and the fact that this study was one of the few to diagnose, among etiological types of dementia, mixed dementia (Alzheimer disease associated with Vascular Dementia), which may in turn have lowered the rates of Vascular Dementia. However, additional studies in South America are necessary to investigate the distribution of etiological types of dementia in communities from the region.

Increased Alzheimer disease/Vascular Dementia ratio in centenarians indicates a higher influence of age on cases of Alzheimer disease, in comparison with cases of Vascular Dementia, supporting the findings of Jorm et al. (1987) ${ }^{1}$ and Hebert and Brayne (1995). ${ }^{63}$ Two Japanese studies described results that illustrated a historical change in the Alzheimer disease/Vascular Disease ratio in Japan, as GukHee and Ajit (2001) $)^{64}$ had previously stated. The study by Ogura et al. (1995) ${ }^{31}$ indicated an inversion of this ratio, observed in earlier studies that demonstrated predominance of Vascular Dementia, perhaps explained by lower rates of 
cardiovascular diseases in the population studied. In the study by Kiyohara et al. (1994), ${ }^{30}$ the Alzheimer disease/Vascular Dementia ratio showed an increase over a time frame of seven years, possibly because rates of Cerebrovascular Accidents among men in the studied population had lowered. However, it is necessary to point out that the analysis of dementia subtypes must be considered cautiously given approximately $55 \%$ of the viable studies for this purpose used specific instruments (NINCDS-ADRDA, NINDS-AIREN or Hachinski Ischemic Scale) while only $25 \%$ performed computerized tomography and laboratory studies.

Age also influenced rates of prevalence across all analyses performed, but not homogeneously. Supporting the results of the descriptive analysis for the age variable, the statistical models tested indicated a decrease in the influence of age in older age groups, as illustrated in the modified logistic model. This result confirmed the meta-analysis published by Ritchie and Kildea $(1995)^{5}$ which stated that the prevalence rates of dementia did not increase exponentially as age increases, as Jorm et al. (1987) ${ }^{1}$ had suggested previously. The data available allowed the supposition that there might be a plateau of prevalence rates above the age of 90 years old. Nevertheless, it is important to bear in mind the hypotheses pointed out by Johanson and Zarit $(1995)^{65}$ - that "mortality could potentially 'lower' the rates of prevalence of dementia in older age ranges" - and by McGee and Brayne (1998) (66 $^{6}$ "once mortality is taken into account, incidence must continue to rise into the oldest groups despite the apparent leveling off of prevalence in the very oldest". Moreover, a recent article by McGee and Brayne (2001), ${ }^{67}$ using a deterministic model, found that only combining extreme changes in mortality, differential mortality and prevalence could lessen the incidence of dementia with increasing age, corroborating the need for more information on the oldest elderly subgroups.

With regard to the considerations presented, the main constraint of this study is the lack of access to a greater amount of data from the studies reviewed. Greater access, allied to systematic examination of incidence studies, could give access to additional information concerning the circumstances that determined the distribution of cases of dementia in the world population.

Our study presented results similar to those of earlier reviews, especially concerning the increase in rates of dementia prevalence parallel to increased age. Regarding this issue, although older elderly were scarce in such studies, there seemed to be a decreased influence of age in older age ranges. Such evidence leads to the assumption that dementia was not related to aging, but to age, as Ritchie and Kildea $(1995)^{5}$ have previously suggested. However, in order to better investigate the relationship between age and dementia rates, it would be essential to control incidence and mortality rates, as pointed out by McGee and Brayne $(1998,2001) .{ }^{66,67}$

The tendency toward a clustering of prevalence rates may have occurred in majority of the studies investigated due to greater homogeneity in diagnostic criteria employed in the studies published between 1994 and 2000.

However, specific regional aspects do exist, such as racial composition, and socio-cultural heterogeneity, especially in regions that have been poorly studied, such as South America and Africa, which justify additional studies on the prevalence and incidence of dementia in developing countries.

\section{References}

1. Jorm AF, Korten AE, Henderson AS. The prevalence of dementia: a quantitative integration of the literature. Acta Psychiatr Scand 1987;76:465-479.

2. Fratiglioni L, Ronchi D, Agüero-Torres H. Worldwide prevalence and incidence of dementia. Drugs Aging 1999;15:365-375

3. Lobo A, Launer LJ, Fratiglioni L et al. Prevalence of dementia and major subtypes in Europe: a collaborative study of population-based cohorts. Neurology 2000;54(Suppl 5):S4-S9.

4. Lopes MA, Bottino CMC. Prevalence of dementia in several regions of the world: analysis of epidemiologic studies from 1994 to 2000. Arq Neuropsiquiatr 2002;60:61-69.

5. Ritche K, Kildea D. Is senile dementia “age-related" or "ageing-related"? evidence from meta-analysis of dementia prevalence in the oldest old. Lancet 1995; 346:931-934.

6. American Psychiatric Association. Diagnostic and statistical manual of mental disorders, $3^{\text {rd }}$ ed. Washington, DC: American Psychiatric Association; 1980.

7. American Psychiatric Association. Diagnostic and statistical manual of mental disorders, $3^{\text {rd }}$ ed (review). Washington, DC, American Psychiatric Association; 1987.

8. American Psychiatric Association. Diagnostic and statistical manual of mental disorders, $4^{\text {th }}$ ed. Washington, DC, American Psychiatric Association; 1994.

9. Hachinski VC, Iliff LD, Zihkla E et al. Cerebral blood flow in dementia. Arch Neurol 1975;32:632-637.

10. McKhann G, Drachman D, Folstein M, Katzman R, Price D, Stadlan EM. Clinical diagnosis of Alzheimer's disease: report of the NINCDS-ADRDA Work Group under the auspice of the department of health and human services task force on Alzheimer's disease. Neurology 1984;34:939-944.

11. Ott A, Breteler MMB, Harskamp F et al. Prevalence of Alzheimer's disease and vascular dementia: association with education. The Rotterdam Study. BMJ 1995; 310:970-973.

12. Prencipe M, Casini AR, Ferretti C, Lattanzio MT, Fiorelli M, Culasso F. Prevalence of dementia in a elderly rural population: effects of age, sex, and education. J Neurol Neurosurg Psychiatry 1996;60:628-633. 
13. Boersma F, Eefsting JA, van den Brink W, Koeter M, van Tilburg W. Prevalence of dementia in a rural netherlands population and the influence of DSM-III-R and CAMDEX criteria for the prevalence of mild and more severe forms. J Clin Epidemiol 1998;51:189-197.

14. Brayne C, Nickson J, McCraken C, Gill C, Johnson AL. Cognitive function and dementia in six areas of England and Wales: distribution of MMSE and prevalence of GMS organicity level in the MRC CFA Study. Psychol Med 1998;28:319-335.

15. Andersen K, Lolk A, Nielsen H, Andersen J, Olsen C, KraghSorensen P. Prevalence of very mild to severe dementia in Denmark. Acta Neurol Scand 1997; 96:82-87.

16. Roelands M, Wostyn P, Dom H, Baro F. The Prevalence of Dementia in Belgium: A population-based door-to-door survey in a rural community. Neuroepidemiology 1994;13:155-161.

17. Lobo A, Saz P, Marcos G, Dia JL, de la Camara C. The prevalence of dementia and depression in the elderly community in a southern european population. The Zaragoza Study. Arch Gen Psychiatry 1995;52:497-506.

18. Pousa SL, Regla JL, Franch V, Pinedo LF. The prevalence of dementia in Girona. Neurologia 1995;10:189-193.

19. Pi J, Olivé JM, Roca J, Masana L. Prevalence of dementia in a semi-rural population of Catalunya, Spain. Neuroepidemiology 1996;15:33-41

20. Manubens JM, Martinez-Lage JM, Lacruz F et al. Prevalence of Alzheimer's disease and other dementia disorders in Pamplona, Spain. Neuroepidemiology 1995;14:155-164.

21. Wernicke TF, Reischies FM. Prevalence of dementia in old age: clinical diagnoses in subjects aged 95 years and older. Neurology 1994;44:250-253.

22. D’Alessandro R, Pandolfo G, Azzimondi G, Feruglio FS. Prevalence of dementia among elderly people in Troina, Sicily. Eur J Epidemiol 1996;12:595-599.

23. Azzimondi G, D’Alessandro R, Pandolfo G, Feruglio FS. Comparative study of the prevalence of dementia in two Sicilian communities with different psychosocial backgrounds. Neuroepidemiology 1998;17:199-209.

24. Strauss E, Viitanen M, Ronchi D, Winblad B, Fratiglioni L. Aging and the occurrence of dementia. Findings from a population-based cohort with a large sample of nonagenarians. Arch Neurol 1999;56:587-592.

25. Fichter MM, Meller I, Schröppel H, Steinkirchner R. Dementia and cognitive impairment in the oldest old in the community. Prevalence and comorbidity. Br J Psychiatry 1995;166:621-629.

26. Ravaglia G, Forti P, Ronchi D et al. Prevalence and severity of dementia among northern Italian centenarians. Neurology 1999;53:416-418.

27. Shaji S, Promodu K, Abraham T, Roy KJ, Verghese A. An epidemiological study of dementia in a rural community in Kerala, Índia. Br J Psychiatry 1996;168:745-749.

28. Yamada M, Sasaki H, Mimori Y et al. Prevalence and risks of dementia in the Japanese population: RERF'S adult health study Hiroshima subjects. J Am Geriatr Soc 1999;47:189-195.

29. Komahashi T, Ohmori K, Nakano T et al. Epidemiological survey of dementia and depression. Jpn J Psychiatry Neurol 1994;48:517-526.

30. Kiyohara Y, Yoshitake T, Kato I et al. Changing patterns in the prevalence of dementia in a Japanese community: The Hisayama study. Gerontology 1994; 40(suppl 2):229-235.

31. Ogura C, Nakamoto H, Uema T et al. COSEOUP GROUP. Prevalence of senile dementia in Okinawa, Japan. Int J Epidemiol 1995;24:373-380.

32. Shiba M, Shimogaito J, Kose A et al. Prevalence of dementia in the rural village of Hanazono-mura, Japan. Neuroepidemiology 1999;18:32-36.

33. Chandra V, Ganguli M, Pandav R, Johnston J, Belle S, De Kosky ST. Prevalence of Alzheimer's disease and other dementias in rural India. The Indo-US study. Neurology 1998;51:1000-1008.

34. Park J, Ko HJ, Park YN, Jung C. Dementia among the elderly in a Korean community. Br J Psychiatry 1994;164:796-801.

35. Woo JI, Lee JH, Yoo K, Kim C, Kim Y, Shin YS. Prevalence estimation of dementia in a rural area of Korea. J Am Geriatr Soc 1998;46:983-987.

36. Liu C, Lin R, Chen Y, Tai C, Yen Y, Howng S. Prevalence of dementia in a urban area in Taiwan. J Formos Assoc 1996;95:762-768.

37. Lin R, Lai C, Tai C, Liu C, Yen Y, Howng S. Prevalence and subtypes of dementia in southern Taiwan: impact of age, sex, education, and urbanization. J Neurol Sci 1998;160:67-75.

38. Liu H, Lin K, Teng EL et al. Prevalence and subtypes of dementia in Taiwan: a commmunity survey of 5297 individuals. J Am Geriatr Soc 1995;43:144-149.

39. Chiu HFK, Lam LCW, Chi I et al. Prevalence of dementia in Chinese elderly in Hong Kong. Neurology 1998;50:1002-1009.

40. Asada T, Yamagata Z, Kinoshita T et al. Prevalence of dementia and distribution of apoE alelles in Japanese centenarians: an almost-complete survey in Yamanashi Prefecture, Japan. J Am Geriatr Soc 1996;44:151-156.

41. Hendrie HC, Osuntokun B, Hall K et al. Prevalence of Alzheimer's disease and dementia in two communities: $\mathrm{Ni}$ gerian Africans and African Americans. Am J Psychiatry 1995;152:1485-1492.

42. Beard CM, Kokmen E, O'Brien PC, Kurland LT. The prevalence of dementia is changing over time in Rochester, Minnesota. Neurology 1995;45:75-79.

43. Graves AB, Larson EB, Edland SD et al. Prevalence of dementia and its subtypes in the Japanese American population of King County, Washington State. The Kame Project. Am J Epidemiol 1996;144:760-771.

44. Fillenbaum GG, Heyman A, Huber MS et al. The prevalence and 3-year incidence of dementia in older black and white community residents. J Clin Epidemiol 1998;51:587-595. 
45. Breitner JCS, Wyse BW, Anthony JC et al. APOE-e4 count predicts age when prevalence of $\mathrm{AD}$ increases, then declines. The Cache County Study. Neurology 1999;53:321-331.

46. McDowel I, Hill G, Lindsay J et al. Canadian Study of Health and Aging: study methods and prevalence of dementia. Can Med Assoc J 1994;150:899-913.

47. Ebly EM, Parhad IM, Hogan DB, Fung TS. Prevalence and types of dementia in the very old: results from the Canadian study of health and aging. Neurology 1994;44:1593-1600.

48. Powell A. Senile dementia of extreme aging: a common disorder of centenarians. Dementia 1994;5:106-109.

49. Farrag AF, Farwiz HM, Khedr EH, Mahfouz RM, Omran SM. Prevalence of Alzheimer's disease and other dementing Disorders: assiut-upper Egypt study. Dement Geriatr Cogn Disord 1998;9:323-328.

50. Ogunniyi A, Gureje O, Baiyewu O et al. Profile of dementia in a Nigerian community: types, pattern of impairment, and severity rating. J Natl Med Assoc 1997;89:392-396.

51. Herrera Jr E, Caramelli P, Nitrini R. Estudo epidemiológico populacional de demência na cidade de Catanduva - Estado de São Paulo - Brasil. Rev Psiq Clín (São Paulo) 1998;25:70-73.

52. Henderson AS, Jorm AF, Mackinnon A et al. A survey of dementia in the Canberra population: experience with ICD-10 and DSM-III-R criteria. Psychol Med 1994; 24:473-482.

53. World Health Organization. International classification of diseases, $10^{\text {th }}$ ed. Mental and behavioral disorders. Geneva: World Health Organization; 1987.

54. Roth M, Tym E, Mountjoy CQ et al. CAMDEX A standardised instrument for the diagnosis of mental disorders in the elderly with special reference to the early detection of dementia. Br J Psychiatry 1986;149:698-709.

55. Hughes CP, Berg L, Danziger WL. A new clinical scale for the stating of dementia. Br J Psychiatry 1982;140:566-572.

56. Blessed G, Tomlinson B, Roth M. The association between quantitative measures of dementia and of senile change in the cerebral grey matter of elderly subjects. Br J Psychiatry 1968;114:797-811.
57. Román GC, Tatemichi TK, Erkinjuntti T et al. Vascular dementia: Diagnostic criteria for research studies: report of the NINDS-AIREN International Wokshop. Neurology 1993;43:250-260.

58. Morris JC, Heyman A, Mohs RC et al. The consortium to establish a registry for Alzheimer's disease (CERAD). Part I. Clinical and neuropsychological assessment of Alzheimer's disease. Neurology 1989;39:1159-1165.

59. Copeland JRM, Dewey ME, Griffiths-Jones HM. Computerised psychiatric diagnostic system and case nomenclature for elderly subjects: GMS and AGECAT. Psychol Med 1986;16:89-99.

60. Folstein MF, Folstein SE, McHugh PR. Mini Mental State: a pratical method for grading the cognitive state of patients for the clinician. J Psychiatr Res 1975;12:189-198.

61. Hebert LE, Scherr PA, McCann JJ et al. Is the risk of developing Alzheimer's disease greater for women than for men? Am J Epidemiol 2001;153:132-136.

62. Corrada M, Brookmeyer R, Kawas C. Sources of variability in prevalence rates of Alzheimer's disease. Int J Epidemiol 1995;24:1000-1005.

63. Hébert R, Brayne C. Epidemiology of vascular dementia. Neuroepidemiology 1995;14:240-257.

64. Guk-Hee S, Ajit S. A review of the epidemiological transition in dementia: cross-national comparisons of the indices related to Alzheimer's disease and vascular dementia. Acta Psychiatr Scand 2001;104:4-11.

65. Johanson B, Zarit S. Prevalence and incidence of dementia in the oldest old: a longitudinal study of population-based sample of 84-90-year-olds in Sweden. Int J Geriatr Psychiatry 1995;10:359-366.

66. McGee MA, Brayne C. The impact on prevalence of dementia in the oldest age groups of differential mortality patterns: a deterministic approach. Int J Epidemiol 1998;27:87-90.

67. McGee MA, Brayne C. Exploring the impact of prevalence and mortality on incidence of dementia in the oldest old: the sensitivity of a deterministic approach. Neuroepidemiology. 2001;20:221-224. 